\title{
The Surveying of the Customer Relationship Management Effectiveness in Governmental Organizations and Estimated Optimal Pattern: Case Study: Sistan and Baluchestan Province
}

\author{
Hossein Askaripoor ${ }^{1}$, Mehdi Shir Afkan ${ }^{1}$, Morteza Sayareh ${ }^{1} \&$ Mojtaba Mohammadnejadi Moodi $^{1}$ \\ ${ }^{1}$ School of Management and Human Sciences, Chabahar Maritime University, Chabahar, Iran \\ Correspondence: Hossein Askaripoor, School of Management and Human Sciences, Chabahar Maritime \\ University, Chabahar, Iran. Tel: 98-936-988-4443. E-mail: askaripoor@cmu.ac.ir; ahmadi.pm@gmail.com
}

Received: May 2, 2013 Accepted: May 17, 2013 Online Published: September 29, 2013

doi:10.5539/par.v2n2p159 URL: http://dx.doi.org/10.5539/par.v2n2p159

\begin{abstract}
For optimizing the efficiency and giving the effective services to customer, there are many methods which have been proposed in different countries. In our country (Iran) to increase the satisfaction of client to organizations, "Respect for client project" in organization service was approved to the highly organization council. The goal of this study is characterization of the effective parameters in respect for client project which must be ordered by Analytical hierarchy process. This project was done in Sistan and Baluchestan province in two stages. The first one for identification of effective parameter on the mentioned plane will be taken the function (bases) of evaluation form in planning and management organization. At second step, these indexes were gathered and ordered by AHP questionnaire between chairmen and experts of 8 governmental systems and university professors.

After this step, the indexes were ranked with AHP method. With analysis of the results in notifying group, making the service and instructing place was allocated the highest ranking and ethical prism initialization in lowest of importance, as staff job behavior group avoid discriminating and obtaining the arrangement in occupational activity have the highest and lowest importance. Orderly, in the 3rd group, official space and equipment, location office automation has the highest priority and also occupational dimensions of office are in the lowest priority. As the latest group, the highest and lowest priorities were dependent on the rationality of required documents and announcement of the price satisfaction.
\end{abstract}

Keywords: customer relationship management, public affairs, quality of services, AHP technique

\section{Introduction}

Mitigation of citizens' trust to government and governmental organs is a major problem in a growing community. One of the orientations of new public management is customer - orientation and clients' satisfaction. In official and administrative regime, satisfaction is considered as a main indicator to measure the efficiency and development of such system.

Unfortunately, despite of increasing apparent update of organizational structure and utilizing state-of-the-art technologies which lead into easy service delivery to customers, Iranian official system is yet experiencing low customer - orientation culture. To this end, initiatives like seven official transformation plan to promote and retain generosity in order to respect the clients were approved by the cabinet as the most important factor in organizational survival. Respect to client project enjoys a high status since it is inspired by Holy Quran teachings. Obviously, this project is bilateral: on the one hand, it values the generosity and rights of people and, on the other hand, it shows that to what extent disrespecting the rights and legal demands of people has led into people's complaints so that in Islamic Republic of Iran, the authorizes are convinced to provide a solution and to execute such plan finally (Moosavi, 2005: 22).

Management and Planning Organization were assigned to undertake this project and it obliges other governmental organizations to undertake it by announcing its approvals. Organizations execute this project via clients' satisfaction indicators determined by Management Organization. Government allotted a budget for all organizations covered by this plan in order to be spent for this project uniquely. Each year, Management Organization distributes a questionnaire among covered organizations to study the rate of execution and to measure clients' satisfaction on delivered services in order to clarify the rank of each organization in its group. 
Despite of paramount importance of respect to client project and remarkable allotted budgets to governmental organizations, preliminary studies by experts and academic professors indicate that this questionnaire does not cover all aspects and indicators to respect the clients and clients' satisfaction and it needs a scientific basis for prioritizing and rating such indicators so that this questionnaire should be able to reflect clients' attitudes and to show their satisfaction of this project actually.

Thus, this study aims at determining the Clients' Satisfaction codified and prioritized criteria in order to create a very exact tool, on the basis of the mathematical method (AHP) for measuring the clients' satisfaction in the organizations which should obey the Clients' Respect Act, and as a result ranking these organizations.

And in this regard, important questions are asked: are important to affecting factors on client respect identified? Do they have similar importance for clients? Present study looks for a proper response for mentioned questions.

Based on this introduction, and in order to reach the goals set in this study, the following questions were raised.

1. What are the main factors influencing the Clients' Satisfaction?

2. How are these main factors prioritized according to AHP method?

\section{Review of the Related Literature}

There are so many organizations around us these days. In fact, organizations and being organized are considered as the main and basic features of the modern societies. We are always in contact with different organizations often without understanding their existence and roles in the society. Understanding the role of the organizations is vital due to their large number and variety. Therefore, it seems necessary to review their roles in and their effects on our life.

Despite all the categorizations of organizations, every organization, whether small, average, or big, determines some certain priorities and sets some goals in its different sections such as private, cooperative, and state, among which the most important ones are related to the clients. Obviously, the only meaningful and permanent way to help organizations reach their goals is to meet their clients' needs through improving their routine process of getting the job done (Arthur \& Irving, 1992: 43). Considering the importance of this issue, we understand that paying due attention to the clients and meeting their needs is of vital importance. And to reach this goal, the optimal Clients Relationship Management is quite necessary. Clients Relationship Management can be studied in both state and private sectors. In this research, Clients Relationship Management in the state section has been studied, with reference to the Clients Respect Act, and considering the studies conducted by outstanding figures such as Smith (1993), Zeithamel \& Mary (2003), Garvin (1987), Moloney (2006), and Parasuraman, et al (1985). It analyzes the quality of the service offered in four quite distinct sections.

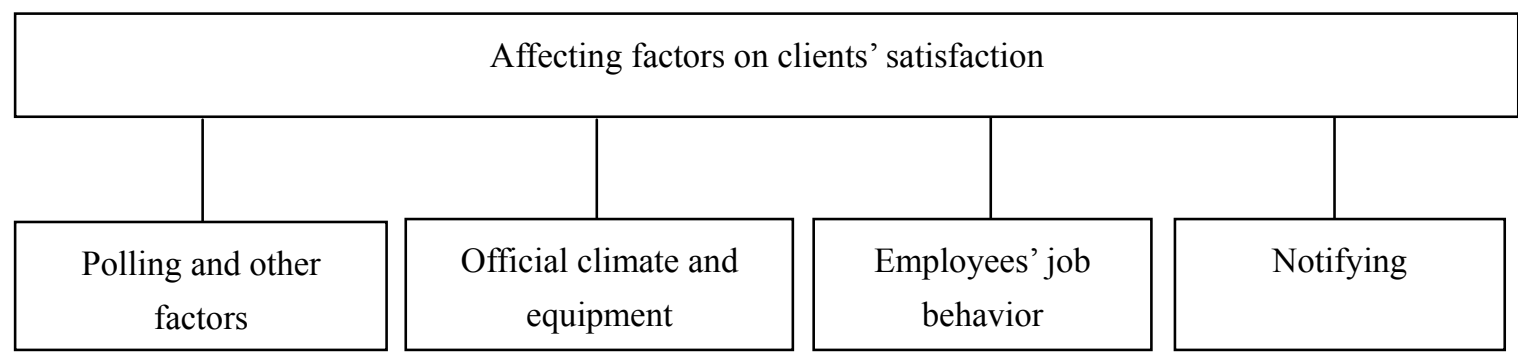

Figure 1. Affecting factors on clients' satisfaction

\subsection{Clients Respect Act}

The main goal of implementing this project is to make the Iranian organizations official system more efficient. The Management and Planning Organization of Iran started the project in 2002. It was approved by the cabinet, and one week later, it was announced as one of the Seven Programs for Reforming the Iran Administrative System. A detail of "Clients Respect and Satisfaction in the Administrative System Act" were approved on April 2002 in a session in the Supreme Administrative Council, and was served upon all the governmental organizations. This project, with the main goal of increasing public trust in the administrative system, is the biggest achievement and support for the country's administrative system.

In accordance with this enactment, all the ministries, organizations, institutions, and governmental firms, all the firms and institutions which should obey this regulation such as police force, municipalities, banks, insurance 
companies, and even the other public non-governmental organizations which use the government budget must take some preplanned steps in order to satisfy the clients and respect them fully.

\subsection{Giving Information}

People who go to governmental organizations usually do not know where to start and where to finish. What kind of documents and deeds do they need? How long does it take to get the work done? Whom should they refer to? They should find the answers to all these questions by trial and error. They usually ask the first person they see, or enter the first room they face and then go from room to room to get the work done. Unfortunately, there is no such a section called "Information desk" to inform the people, and they usually ask the gate guards their questions. (Taher Khani, 2003: 33-34)

Government sector clients need the exact and immediate information easily accessible. If one can get the information from the needed office through a telephone call, this aspect of quality is improved. If the person cannot make the telephone call, the client should go to the office himself and find the information the notice board or through the central computer available at the entrance. If these two ways could not help, having someone at the entrance to give the information to the clients will be quite useful.

This aspect includes all the factors related to informing and guiding the clients in all the different parts such as how the service is offered, knowing the different services, the administrative procedure, all the information related to the staff like their names, positions, and even teh position of their office. It also includes the electronic, mail, and cell phone services.

\subsection{Reforming the Existing Administrative Method and Procedure}

In the governmental organizations, the way service is offered is as important as the service itself. The way the staff treats the clients should be monitored. If the services and activities done in this section do not follow certain rules, people will soon be dissatisfied. Thus, obeying the rules is one aspect of the quality. People want the service to be offered quickly and with very little bureaucracy. Another aspect of the quality is that how simple the routine process of the job is. Following the rules and regulations is not an end in itself, but a means to reach another important goal which is to get the job done simply. In giving service to people, the staff should be flexible in applying the rules. How the service is given is so important that not only the governmental organizations, but also the state firms and companies which are not giving service have given priority to the clients' satisfaction in order to survive (Zameni, 2001: 20).

This includes the staff's behavior toward the clients, being polite, good conduct, feeling responsible in doing the job assigned to them, doing the job carefully and quickly, being on time, spending the office time for the job not for personal matters, avoiding pulling the strings for relatives, being just and fair, abiding by the laws, and being committed to the office laws and regulations, and finally being neat and regular.

\subsection{Supervising and Monitoring the Administrative System}

The most important and vital issue in this project is the monitoring. In all management systems, it is impossible to monitor the activities, based on the determined framework, from the beginning to end without official and semiofficial supervision. Indeed, continuous monitoring, whether tangible or not, is the only logical and necessary technique to reach justice in the Clients' Respect Project.

In order to monitor the implementation of this project, the function of the organization in offering the service can be studied. This helps us understand this important point that if the Clients' Respect Project is really acted upon and followed or it is just a formality and nobody pays attention to that. Are the staffs following this law and do they see it as a basic rule? If the staffs look at monitoring as a key factor in this project, they will see themselves responsible in monitoring their own behavior, words, and function of the organization. As a result, they themselves monitor the organizations' activities.

Imam Ali in his $53^{\text {rd }}$ letter in his book entitled "Nahjolbalaghe" emphasized the role of direct monitoring in administration which should be carried out very carefully, and believes that those who do not obey the rules should be punished. Indeed, he describes this punishment as the real meaning of justice for the law-breakers, and wants to let the people remember the meaning of justice, and make it a very basic maxim for human (Imam Ali, 2001).

\subsection{The Office Space and Equipments}

This aspect of the project includes the organization clean space, the facilities provided for the clients, the arrangement and order of the different units for facilitating the process of giving service, up-to-date system, administrative automation, and other facilities provided for the disabled. 


\subsection{Survey}

If an organization aims to be considered successful in issues such as joint management, clarifying its policies, being client-oriented, and making people content, it must certainly have a deep understanding of the public opinion, and respect that. This is quite impossible unless they provide a channel through which a close, mutual and logical relationship is established between people and the organization. This might include giving some questionnaires to the clients to ask their opinion about the quality of the services offered by the organization, and then comparing these realities with the ideal state for which the organization has planned. It also includes reflecting and thinking about the feedback that the clients provided about the organization, seeing to the clients complaints, and justifying that the budget and the documents, which the clients should provide, are logical.

\subsection{Environmental Factors: An Important Factor Influencing the Clients' Satisfaction}

In every organization, the clients and customers ease of access to the services offered is vitally important. (Maadi, 2003: 41-46)

Outside-organization Relationship includes:

a. Giving the necessary information and advertisements

b. Public relation with people

c. Holding ceremonies, celebrations, and exhibitions (ibid).

\subsection{Total Quality Management in the Governmental Organizations}

The idea of the Total Quality Management was first proposed for the manufacturing section, but it gradually influenced and entered the government offices. Many of the offices in the government sector have utilized the Total Quality Management based on some certain clients oriented approaches in the recent years.

In Political Decentralization Theory and Quality-based Approach, it is very much emphasized that the client is the base and main element, and all the decisions should be made in order to satisfy the client. In this approach, the Total Quality Management offers a better method than Vebrianism for governmental organizations. For the same reason, Total Quality Management is a far approach better than Taylorism in the private sector (Madsen, 1995, p, $10)$.

Table 1. Different aspects of the total quality management for the government sector

\begin{tabular}{lc}
\hline \multicolumn{1}{c}{ Description } & Aspect \\
\hline $\begin{array}{l}\text { The accurate and exact information should be accessible to all and be given to } \\
\text { clients quickly }\end{array}$ & Giving Information \\
The clients in the government section want the service to be offered quickly & Offering the services quickly \\
The clients want the staff to do the job correctly with proper results & Offering the proper service \\
$\begin{array}{l}\text { The clients want the office correspondence, activities, and facilities to be } \\
\text { enjoyable }\end{array}$ & $\begin{array}{c}\text { Attractive atmosphere of the } \\
\text { service office }\end{array}$ \\
$\begin{array}{l}\text { The clients expect the office staff to behave kindly in giving the service } \\
\text { People ask for a system that obeys the rules and does not discriminate among } \\
\text { them }\end{array}$ & $\begin{array}{c}\text { Good Treatment } \\
\text { People like their job to be done in a simple and straight manner, not with too } \\
\text { much bureaucracy }\end{array}$ \\
$\begin{array}{l}\text { People want the staff not to be too strict with the rules, and regulations } \\
\text { Souness }\end{array}$ & $\begin{array}{c}\text { Simplicity and } \\
\text { straightforwardness }\end{array}$ \\
\end{tabular}

Source: Alvani and Riahi, 2003, p, 48

\section{Methodology}

This is descriptive - surveying study since the author studies the organizations through a field study. Likewise, it is conducted by questionnaire and interviews. In terms of purpose, this studies attempts to provide a model for improving client measurement process on official system and to provide a balanced tool to rank affecting indicators on customers' satisfaction by library and Internet studies and polling from elite experts as well as the 
members of official transformation commission in relevant community. Therefore, this is an applied research in terms of its purpose.

\subsection{Statistical Population}

The unit analysis in this research is organization which includes eight groups of governmental companies based on their categorization by Sistan and Baluchestan Planning Organization in the Respect Project Polling in 2010. As follows:

- Chabahar Finance and Economy Organization

- Zahedan Finance and Economy Organization

- Zahedan Central Melli (National Bank)

- Zahedan Jihad and Agriculture Organization

- Zahedan social Welfare Organization

- Zahedan Governor's Office

The statistical sample of this study is chosen purposefully. They were 30 persons chosen from the experts and experienced staffs of the organizations who had worked there for at least 25 years and preferably served in the Administrative Reform Committee. In order to gather the necessary data from this sample, the researcher made a questionnaire based on the available literature in the semi-open-end format, and sent to the people chosen for the study. 25 of the questionnaires were sent back with the necessary information. Thus, the data of the study was taken from these 25 questionnaires, and then analyzed by the EC Software.

To ensure the validity of the questionnaire, it was analyzed and approved by the researchers and experts of those organizations. Furthermore, to measure the reliability of the questionnaire, the incompatibility rate of the ranking of the indices was 0.025 .

\section{Data Analysis}

\subsection{Drawing the Hierarchical Graph of Affecting Factors on Respect to Client}

In ranking step, AHP model (ghodsi poor, 2005) was considered. There exists a standard for this method. The first step was to establish a hierarchical structure shown in graph 2.

To rank factors on respect to client, it was necessary to distribute two types of questionnaires. The first questionnaire was devised to rank and weight four factors of the second level (after purpose level). It was distributed among 10 management professors. Due to the importance of ranking in this level, it was completed by university professors.

Hierarchical graph of the research is outlined below.

The quantity of comparisons on four measures of the second level was six based on $\frac{n(n-1)}{2}$ formula. Data were analyzed by Expert Choice software and the results are shown in figure 2.

Among four identified indicators, employees' job behavior (0.453) has the highest importance and official space and equipment $(0.173)$ has the lowest importance. Notifying $(0.189)$ and other factors $(0.187)$ achieved the second and third ranks respectively.

The second questionnaire was distributed based on the selection of practitioners and elites of seven companies explained before. In this questionnaire, 143 pair comparisons were conducted namely 45 comparisons for notifying sub-measures, 55 for employees' job behavior, 28 for official space and equipment and 15 ones for polling and other factors. The data from the gathered 25 questionnaires were analyzed by the EC software, the results of which are summarized below.

\section{A. Ranking notifying options}

This group consists of:

- Installing signpost for clients' needed information

- Installing incumbents' specifications and terms of references

- Providing notifying brochures or handbooks

- A computer to access needed information 


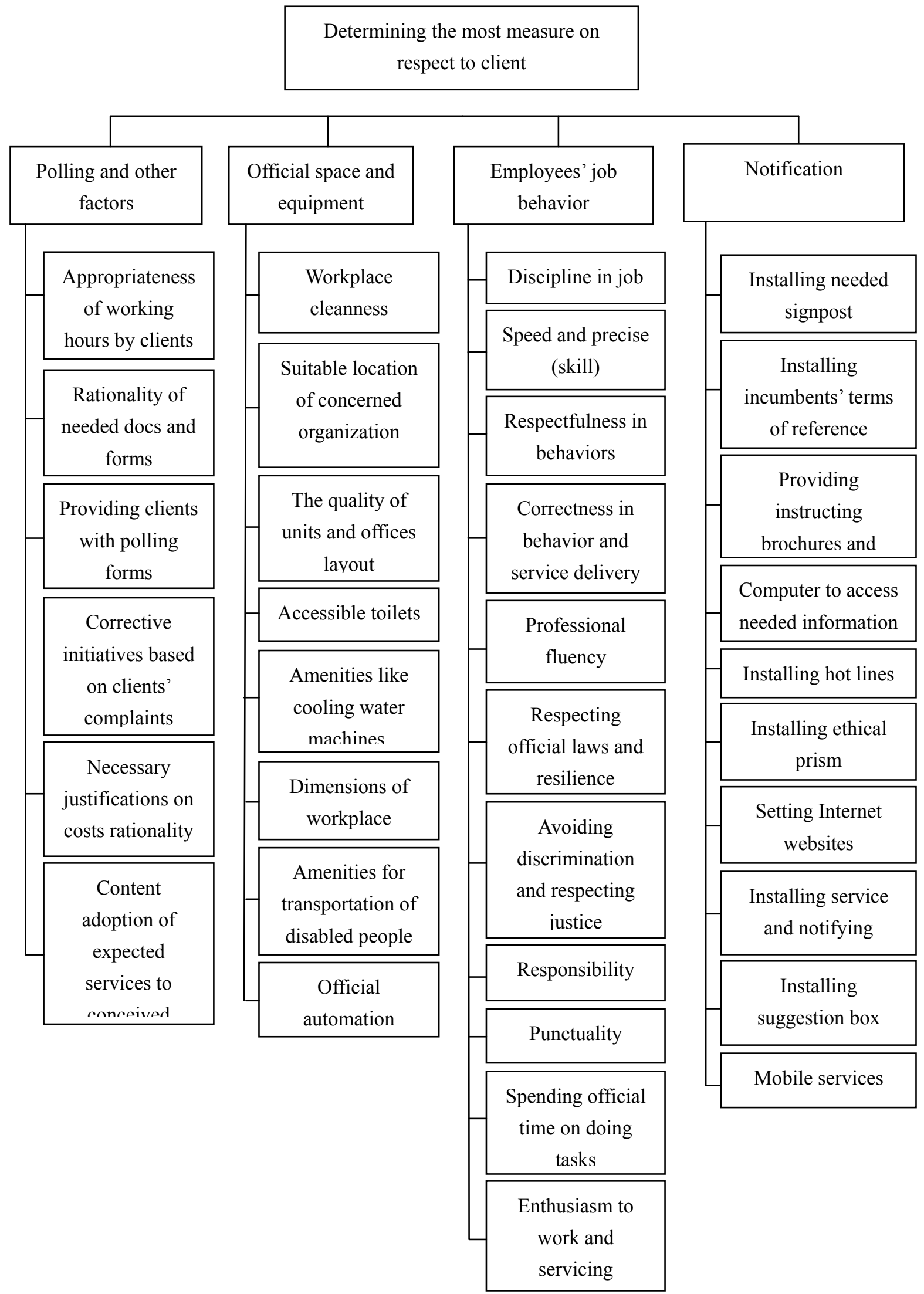

Graph 1. Hierarchical structure of the clients' respect indices 


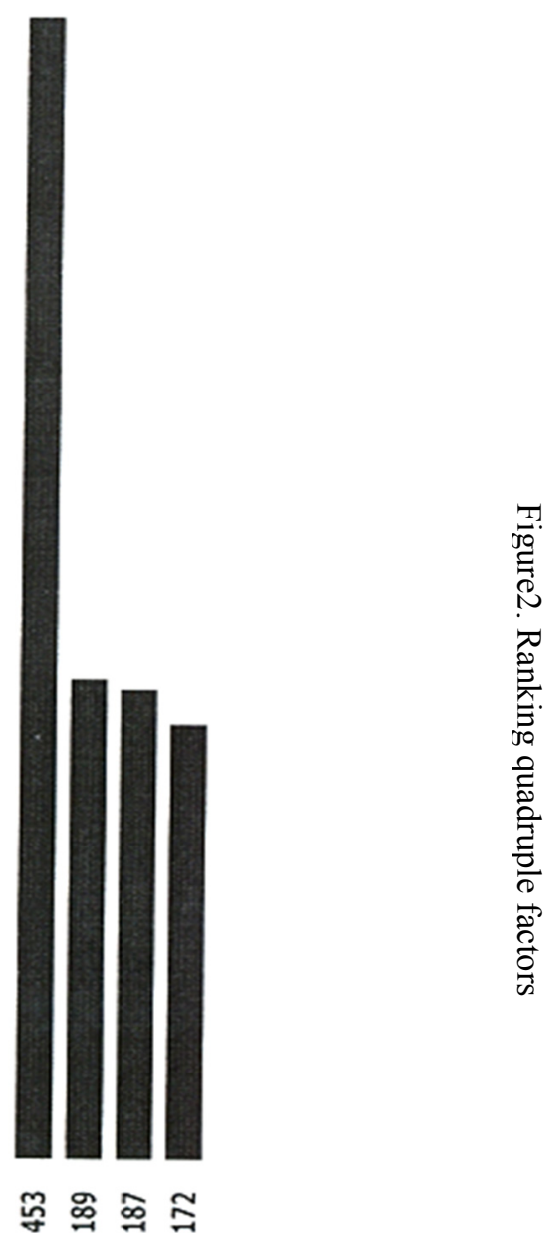

- Installing hot lines

- Installing ethical prism

- Internet website

- Establishing servicing and notifying places

- Suggestion box

- Mobile services 
Notifying measures, establishing servicing and notifying places $(0.165)$, hot lines $(0.153)$ and installing signpost for needed information over front door $(0.133)$ ranked 1,2 and 3 respectively while the lowest rank was installing ethical prism (0.050). The rate of incompatibility is 0.030 which confirms our comparison.

\section{B. Ranking employees' job behavior options}

This group consists of:

$>$ Discipline in job

$>$ Speed and precise (skill)

$>$ Respectfulness

$>$ Correctness in behavior and service providing

$>$ Professional awareness

$>$ Respecting official laws and rules and resilience

$>$ Avoiding discrimination, nepotism and justice respect

$>$ Responsibility

$>$ Punctuality

$>$ Spending official time on doing the tasks

$>$ Enthusiasm to work and servicing

Avoiding discrimination and respecting justice $(0.155)$ has the highest priority followed by respectfulness $(0.131)$ and employees' responsibility (0.126). The lowest rank was employees' discipline $(0.060)$. The rate of incompatibility was 0.01 .

\section{Ranking official space and equipment}

This group consists of:

- Workplace cleanness

- Suitable location of referred unit

- The quality of units and offices layout

- Accessible toilets

- Suitable amenities such as cooling water machine, chair, warming and cooling systems

- Dimensions of workplace

- Amenities for the transportation of disables people

- Official automation and avoiding surplus bureaucracy

D. Ranking polling and other factors options

This group consists of:

- Appropriate time to provide services

- Rationality of needed docs and forms and their information

- Providing clients with polling forms

- Announcing remedial initiatives based on clients' previous complaints

- Announcing necessary justifications based on the rationality of costs paid by clients

- Content adoption of received services and expected services

Rationality of docs $(0.234)$ and remedial initiatives $(0.181)$ had the first and the second ranks and lowest one was announcing cost justifications (0.114). The rate of incompatibility was 0.03554 which confirms the reliability of our comparison.

\section{E. Ranking all options against each other}

In figure 3, all measures in four groups are compared against each other in which avoiding discrimination, nepotism and justice respect $(0.081)$ has the highest importance followed by respectfulness $(0.068)$ and responsibility in job (0.066). The lowest ranks are dimensions of workplace $(0.009)$, accessible toilets $(0.010)$, installing ethical prism (0.011) and installing suggestion box (0.011). Noteworthy, the rate of incompatibility is 
0.02 which is less than 0.1 and confirms the comparison. As seen in graph, the highest priority is evaluated for employees' job behavior.

Aim: determining the most important measure the respect to client

Total Incompatibility: 0.02

Avoiding discrimination, nepotism and justice respect

Respectfulness

Responsibility

Correctness in behavior and servicing

Respecting official laws and rules and flexibility

Enthusiasm to job and servicing

Precise and rapid action (skill)

Establishing service and notifying places

Professional fluency and awareness

Punctuality

Spending working time on doing the tasks

Rationality of needed forms and docs

Hot lines

Discipline in work

Official automation and avoiding bureaucracy

Installing signposts

Appropriateness of services time

Content adoption of received services with expectations

Setting up an Internet notifying website

A computer to access needed information

Providing clients with polling forms

Providing notifying brochures and handbooks

Mobile services

Proper location of units

The quality of units and workplaces layout

Amenities such as cooling water machines, chairs, warming and cooling systems

Amenities for transportation of disabled

Announcing necessary justifications on rationality of costs paid by clients

Installing incumbents' terms of reference

Workplace cleanness

Installing suggestion box

Installing ethical prism

Accessible toilets

Dimensions of workplace

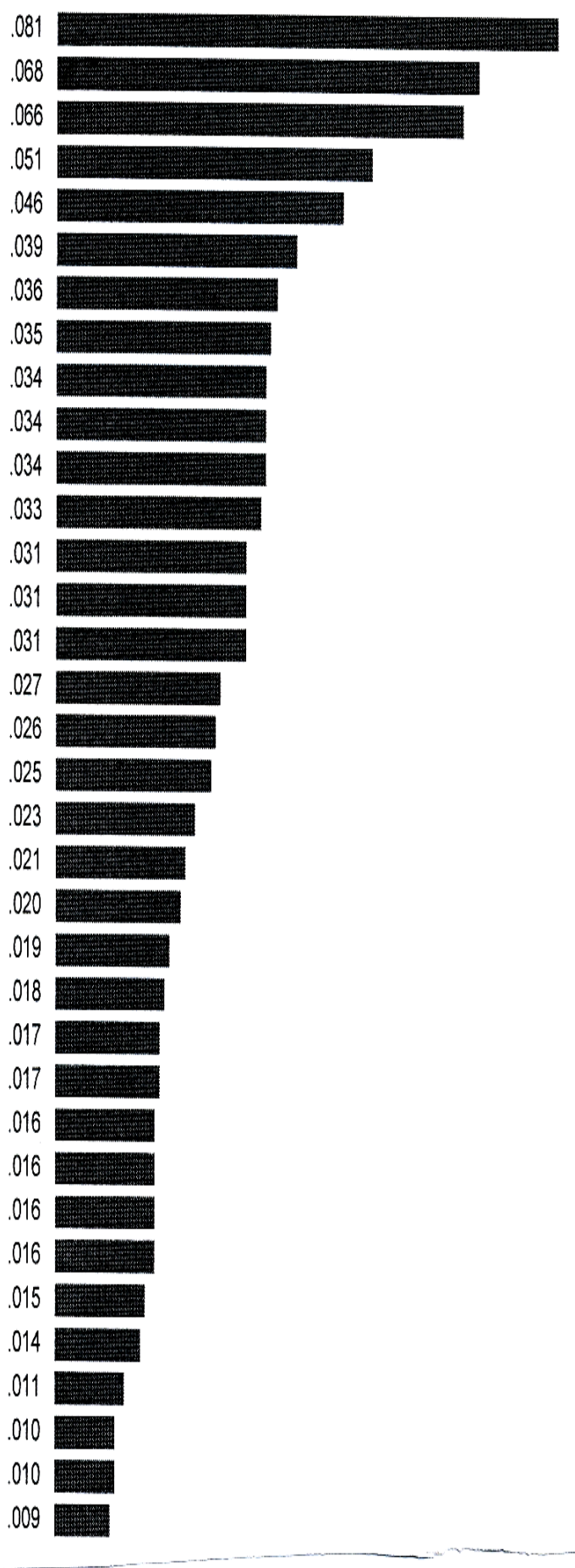

Figure 3. Final ranking of all indicators 


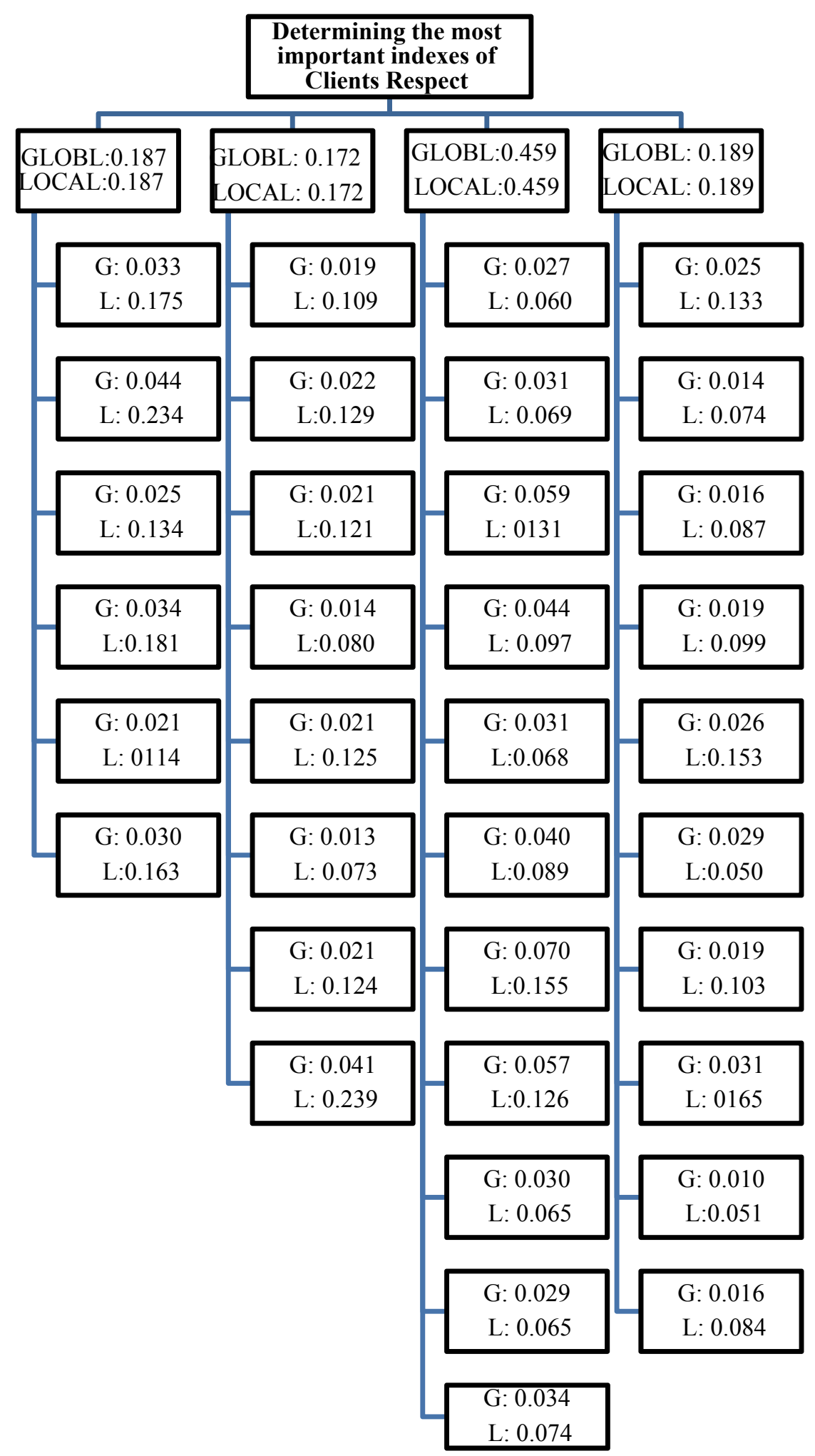

Graph 2. The global and local weights of the hierarchical indices and factors

Final weight for each level of hierarchy is shown in graph 2 completely in LOCAL weight namely the weight of each sub-branch to head-branch and GLOBAL weight namely the weight of each sub-branch to aim. The total LOCAL weight is 1 in each branch and the total GLOBAL weight is 1 in each sub-branch which is the same weight of aim level. In other words, the weight of each sub-branch is shown proportionate to the higher level of that sub-branch in LOCAL weight. For example, the weight of installing signpost for needed information is 0.133 in 
Local weight. It means its weight to its head-branch namely notifying factor. Its GLOBAL weight is 0.025 which indicates its weight to the aim level namely all identified measures. The below figure is the same as Figure 1, but all the weights have been added here.

\section{Conclusion}

In answering the first question of the research regarding the affecting factors on clients' respect and satisfaction, 4 groups of factors were identified: notifying indicators group, employees' job behavior indicators group, official space and equipment indicators group and polling and other factor indicators group. Each group has its own indicators. There are 10 indicators for the first group, 11 for the second group, 8 for the third group and 6 for the fourth group.

In answering the second question regarding ranking such indicators, acquired weights show that the indicators of employees' job behavior group have the highest priority with a huge distance from other groups followed by notifying group, other factors group and official space and equipment group.

Due to relative high priority of the first group to other groups, its indicators normally enjoy higher ranks.

As seen in below graph, $30 \%$ of indicators constitute $50 \%$ of total weight of indicators so that they are considered as the most fundamental measures as follow:

1. Avoiding discrimination, nepotism and justice respect

2. Respectfulness

3. Responsibility

4. Correctness in behavior and servicing

5. Respecting official laws and rules and flexibility

6. Enthusiasm to job and servicing

7. Precise and rapid action (skill)

8. Establishing service and notifying places

9. Professional fluency and awareness

10. Punctuality.

According to acquired results and weights, all indicators are shown as a pattern in figure 4 . On this basis, the distance between weights of indicators is 0.015 . Based on such distance, indicators with 0.015 domains are located in one circle. The order of circles means that organizations should attempt to improve this process by focusing on the most important indicators in order to increase clients' satisfaction. The circles are arranged in a manner in which the most important factors are closer to center. Wider circles, less importance. However, it does not mean that organization should act based on such order. Rather, this model is more focused on more important factors to execute respect to client project and to promote clients' satisfaction. Simultaneously, respecting to other factors is also recommended. 


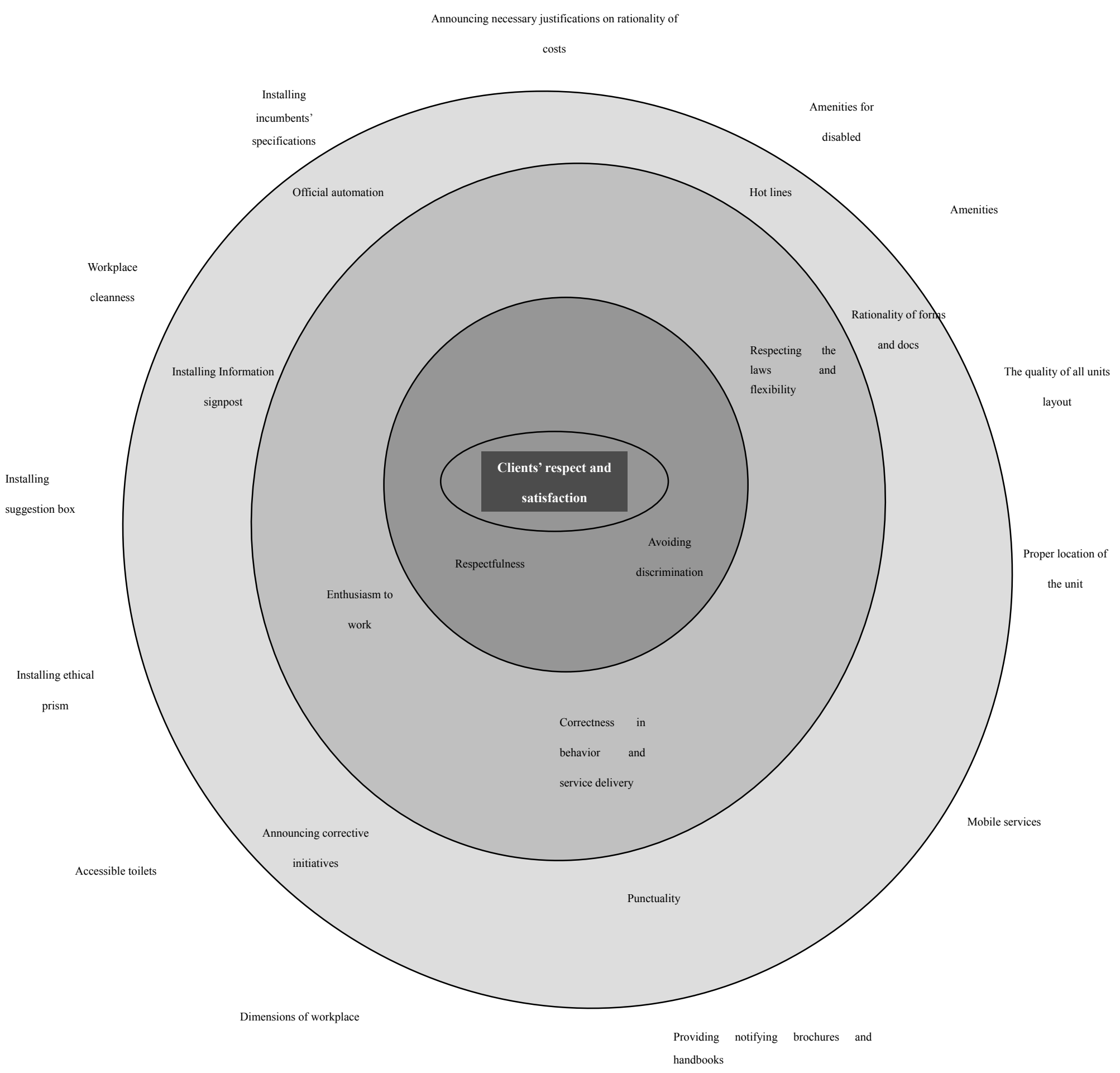

Figure 4. Conclusion 


\section{Research recommendations}

\subsection{Responsibility}

The structure of companies and organizations should be planned in a manner in which only responsible staff can access higher managerial positions. It is undeniable that managerial knowledge and skills can be learnt in work process while responsibility trait as the most fundamental factors of work progress does not create easily. Although in a optimistic treatment to achieve such goal, one can ask employees to be responsible and to act a pattern for other employees and one can expect them to be responsible by following such pattern. However, one should regard the fact that by such methods, we can hope that responsibility morale would be emerged in workplace. In practice, however, there is no trustable guarantee to achieve this important issue since in any organization there are a lot ways to neglect such responsibility. Some psychiatrists believe that responsibility is a trait resulted from an influential decision in a period of human life. In other words, people become responsible under the influence of various social factors. They acknowledge such trait in their life process and they will be responsible in their workplace. Those who have not passes such stage will always neglect the responsibility. Behavioral practitioners divide humans into two groups in terms of their responsibilities: responsible individual who accept the responsibility of everything they do and the people who neglect their responsibility in any condition. Controlling systems in an organization should be in a manner to oblige employees to being responsible. The first recommendation is that monitoring systems should be in a manner so that managers and employees cannot neglect their responsibilities. It needs to identify responsible people with records of commitment to job consciousness.

Encouraging and controlling managers and employees to responsibility have two valuable ramifications: A. changing the way of appointing managers. When managers are assured that they have no option to neglect their responsibility if they accept a managerial position, then they certainly avoid entering to the forum of responsible managers. B. By transformation in monitoring entities. When responsibility is compulsory in an organization, monitoring entities will be faced with radical changes in terms performance and their people and, as a result, the type of relations between monitoring and executive organs will be changes. Anyhow, overcoming on the problem of neglecting the responsibility in hard and time-consuming and any organization which is not able to overcome such difficulties will not only face with more bottlenecks on efficiency and productivity but also its survival in long term will be clouded.

The second recommendation involves training courses to increase the responsibility mentality among employees.

\subsection{Correctness in Behavior, Words and Servicing}

In interviews with clients and practitioners, we achieved this joint point that one of the most fundamental factors of satisfaction is to trust employee's words and behaviors. Trusting means a promise given by an incumbent to a client and the confidence of client to the correctness of employees' words and behaviors. Client expects that an employee commits to what he/she promises. If the clients feel that the employee is committed to work progress, they will be happy. Hence, building commitment and honesty culture among employees is considered among the most fundamental tasks of managers in organization. At the beginning, focusing on such issue shows the will of the organization.

\subsection{Respecting Official Laws and Rules and Flexibility}

It has two aspects:

1. Laws and rules as bureaucratic tools in organization

2. Respecting laws and rules by organizational members

Obviously, laws inflexibility is unendurable like not respecting them. Therefore, it is firstly required to create flexibility, provided that the law integrity is not damaged. It will be performed by top management to prevent the interference of employees' interests. To this end, it needs something like job engineering to analyze organizational laws. Noteworthy, this should be done precisely and by top management coordination. Secondly, it needs to hold briefing and training sessions for employees to brief them with the reasons and benefits of amendments in laws and rules and to explain the results for them to be skilful in laws and rules. Thirdly, monitoring/controlling aspect should be enhanced to record and reflect any breach of laws. Fourthly, punishment systems should be set to treat offenders properly. Fifthly, clients should be able to access organizational laws and rules to expose their opinions. It is possible by publishing handbooks in the archive of the organization.

\subsection{Enthusiasm to Work and Servicing}

Clients feel satisfaction when they see that employees are performing their jobs enthusiastically. It is due to the fact that man naturally feels happy when he/she sees such enthusiasm. 
- One should talk with employees and should be aware of their problems.

- One should attempt to resolve their problems and to make them calm spiritually. When an employee observes that top management pays attention to him/her, then he/she will feel more commitment to his/her job and his/her enthusiasm will be increased.

- Those employees should be encouraged that serve clients patiently and enthusiastically.

\subsection{Establishing Servicing and Notifying Places}

It is considered as s fundamental factor of clients' satisfaction. Therefore, it is necessary those people who work in this section have an ideal level of behavior and politeness. They should be fully aware of positions, people and their terms of references. Being confused in organization is highly fatiguing for clients. There are some recommendations in this regard: briefing and training sessions should be organized for people to make clear the key role and status of people in clients' satisfaction. They should learn that how their proper treatment can optimize employees' working hours and mitigate unnecessary attendance of clients which leads into clients' satisfaction. To encourage such employees to play their organizational role better, it is required to set up a proper awarding system which can be shaped by asking the opinions of clients about their satisfaction of such people.

\subsection{Professional Domination and Awareness}

Commitment and specialty are complementary and lowness or highness of each can scatter the balance. Specialty and domination should be emphasized as equal as commitment and enthusiasm. Therefore:

- Holding training and job learning classes to promote individuals' skills

- Using the expertise of skilful and trained people presumably out of the organization to express skills and to promote them

- Organizing training courses for new employed personnel and focusing on training and learning the skills completely and preventing their occupation before dominating needed skills

\subsection{Punctuality and Spending Official Time on Tasks}

Punctuality points out the fact that employees attend in their workplace during determined time. However, it does not satisfy clients in itself. As mentioned in many organizations, some employees attend in their offices on-time but spend their time on irrelevant affairs in order to waste their time and neglect their responsibilities. It is due to the lack of commitment culture to work which both destroys organizational outlook and creates added costs. It draws a negative picture by which other employees are encouraged to neglect their job. Because of automation of employees' exit/enter the possibility of delay or early leaving will be too limited. Therefore, it is suggested here to treat lazy and uncommitted persons to whom a punishing system should be devised since it is impossible to neglect wasting the resources and delaying clients' works. Therefore, inspectors should monitor the organization regularly.

Organizational emphasis on above issue causes clients' satisfaction rises to $50 \%$ based on research findings. As seen, these few cases consist $30 \%$ of all measures with high weights. Therefore, research general proposal is that organization should increase its main focus on these measures. However, it does not mean to neglect other measures. Suggestions for other measures include:

- Client expects non repetitive and irrational documents requested by the organization. In filling forms, asking unnecessary items should be avoided. It is recommended to revise or recreate the forms.

- Discipline in job and favorable appearance is too important for clients and also impacts on organization effectively. So proper appearance suitable for an Iranian will make clients happy.

- Although hot lines are established in many organizations, many citizens are unfamiliar with them. Therefore, one should attempt to recognize their facilities and advantages in notifying arena. To this end, necessary information should be gathered in organizational brochures. In the meantime, these lines should be rapidly installed in organizations that have not yet established them.

- Although official automation and computerizing of many operations are happened in organizations due to technological progresses, in many aspects the philosophy of official automation existence to increase rapidness and preciseness in performing the tasks has weakened because of bureaucracy in organizations. Although the benefits of official automation do not limit to omission of bureaucracy, it involves advantages such as information security rising, easier analysis of data, better work division among employees, easy information classification, quick access to documents, promoting job satisfaction, work resilience, flexibility, broader monitoring by managers, etc. By considering such benefits, it is obvious 
that organizations should be more active in mechanization and official automation. Overall, these result into client's satisfaction.

- Regarding clients' suggestions/complaints, suggestion boxes are installed in organization. Alone, it does not lead into clients' satisfaction otherwise clients are provided with suitable feedbacks to be aware of corrective measures taken by the organization. Thus, clients are provided with corrective initiatives through installing signposts and publishing in newspapers and weekly journals or through brochures.

- Website and blogs of the organization are highly important in informing those people who use computer and Internet. Therefore, it is proposed that organization runs a website to provide clients with updated information through programming experts.

- The dimensions of organizational units should prevent crowds. Units with more clients should enjoy larger space with amenities such as cooling water machines, chairs, etc. Units with high official affairs and with long waiting period for clients should be beautiful with amenities such tea or warm water. They do not cost a lot but they lead into clients' satisfaction. This was clearly observed during researches.

- The quality of unit layout should make discipline and prevent repetitive going back and forth. This should be done by decorative practitioners.

\section{References}

Alvani, S. M., \& Riahi, B. (2003a). Assessing the Service Quality in the Public Sector. Iran Center of Industrial Research and Education. Tehran.

Alvani, S. M., \& Riahi, B. (2003b). The Modern theory of Total Quality Management in Iran Governmental Sector. Administrative Reform Journal, 41-42.

Arthur, R. T., \& Irving, J. D. (1992). Total Quality Management Three Steps to Continuous Improvement. Addison-Wesley Pub.

Garvin, D. A. (1987). Competing on the Eight Dimensions of Quality. Harvard Business Review. November-December.

Ghodsi poor, H. (2005). Analysis of Hierarchical Process. Amir Kabir Industrial University Press. Tehran.

Imam Ali. (2001). Nahjolbalaghe. Allameh and Sons Publication Company. Tehran.

Maadi, S. (2003). The Relationship between Public Relations and Clients' Respect. Agent and Public Relations Journal, 5, 41-47.

Madsen, O. N. (1995). Public Enterprise and Total Quality Management. Total Quality Management, 6(2), 165-174. http://dx.doi.org/10.1080/09544129550035503

Moloney, C. X. (2006). Winning Your Customer's Loyalty: The Best Tools, Techniques and Practices. AMA Workshop Event(s). San Diego.

Moosavi, S. M. R. (2005). A Glance at Clients' Respect Project and Attracting Clients' Satisfaction in Official Regime. Journal of Eslah and Tarbiat, 131, 4-7.

Parasuraman, A., Ziethaml, V. A., \& Berry, L. L. (1985). A Conseptual Model of Service Quality and its Implications for Future. Journal of Marketing, 49(48). http://dx.doi.org/10.2307/1251430

Smith, K. (1993). Total Quality Management in State Sector. Journal of Public Adminstration, 27, 79-80.

Taher Khani, A. (2003). The Study of Factors Influencing Clients' Satisfaction and prioritizing them in the Ghazvin Province Electricity Power Company. (M. A. thesis). Karaj Center of Management Studies and Research.

Zameni, H. (2001). A Survey and analyzing the dimensions of quality services for foreign student in Ferdowsi University. (paper of Master in Ferdowsi University). Mashhad.

Zeithaml, V., \& Mary, J. B. (2003). Service Marketing (3rd ed.). McGraw Hill.

\section{Copyrights}

Copyright for this article is retained by the author(s), with first publication rights granted to the journal.

This is an open-access article distributed under the terms and conditions of the Creative Commons Attribution license (http://creativecommons.org/licenses/by/3.0/). 